\title{
PRÁTICAS DE LETRAMENTOS DE PROFESSORES DE LÍNGUA PORTUGUESA EM FORMAÇÃO INICIAL: ENTRE A ESCOLA E A UNIVERSIDADE
}

\author{
Gabriela Eckert Pereira* \\ Francieli Matzenbacher Pinton ${ }^{* *}$
}

RESUMO: Assumindo a perspectiva dos estudos sobre letramento, o presente trabalho investiga de que forma professores de língua portuguesa ressignificam suas práticas de letramento no contexto acadêmico. Para tanto, partimos do conceito de eventos de letramentos, compreendido como episódios observáveis que surgem das práticas; e do conceito de práticas de letramento, entendido como os modos gerais de usar a escrita em eventos. O universo de análise compreende um grupo de professores de língua portuguesa em formação inicial, matriculados na disciplina de Produção textual, ofertada no segundo semestre de um curso de licenciatura de uma universidade federal do interior do estado do Rio Grande do Sul. Os dados foram gerados a partir de um questionário semiestruturado, respondido por 31 participantes, cujas questões evidenciaram o processo de ensino e aprendizagem de produção textual na escola e na universidade. Para análise dos dados, foram empregados os procedimentos: i) identificação dos recursos ricos em significação e elaboração de categorias semânticas de análise, ii) comparação entre as práticas letradas experienciadas na universidade e escola e iii) verificação da proximidade/distanciamentos entre as práticas descritas. Os resultados demonstram que os professores em formação compreendem o processo de letramento como individual, focalizando em aspectos estruturais e normativos.

PALAVRAS-CHAVE: Eventos e práticas de letramentos; Formação de professores; Novos estudos do letramento.

\section{Considerações iniciais}

Os estudos sobre leitura e escrita no contexto acadêmico têm colocado em evidência as dificuldades enfrentadas, por grande parte dos graduandos, de lidar com as práticas de leitura e escrita na esfera acadêmica. Pesquisadores como Lea e Street (1998), Gee (1999) e Lillis (2001) demonstram em seus estudos que muitas dessas dificuldades vivenciadas

\footnotetext{
* Mestranda em Estudos Linguísticos do Programa de Pós-Graduação em Letras da Universidade Federal de Santa Maria (UFSM). Integrante do Núcleo de Estudos e Pesquisas em Ensino de Linguagem.

${ }^{* *}$ Doutora em Letras pela Universidade Federal de Santa Maria (UFSM). Professora Adjunto A da UFSM. Coordenadora do Núcleo de Estudos e Pesquisas em Ensino de Linguagem - NEPELIN.
} 
estão relacionadas ao fato de que as convenções que regem o contexto acadêmico são distintas daquelas que orientam a educação básica. Segundo os autores, os graduandos se deparam com práticas letradas diversas daquelas que faziam parte de outros níveis de escolarização, bem como de outros espaços pelos quais circularam antes de ingressar no ensino superior. Sendo assim, pode-se afirmar que, ainda que esses estudantes sejam competentes leitores e produtores de textos, a aquisição dessas novas linguagens não é processada de forma automática. Isso significa que as barreiras relacionadas à compreensão e à produção textual tendem a ser enfrentadas por qualquer discente que ingresse no ensino superior.

As distintas convenções que regem o ensino superior somadas às deficiências oriundas da educação básica relacionadas à produção textual apresentadas por grande parte dos estudantes acarretam inúmeros conflitos e tensões (GEE, 1999). Nesse sentido, há tensões tanto por parte dos alunos quanto por parte dos professores, que, por sua vez, acreditam em grande medida que os discentes devam chegar "prontos" à universidade, e, por isso, não se sentem responsáveis por auxiliá-los no processo de inserção no contexto acadêmico (LEA; STREET, 1998).

Em contexto brasileiro não é diferente, conforme reportam estudos realizados por Marinho (2010) e por Silva e Castanheira (2019). A conclusão de que há necessidade de pesquisas sobre habilidades e competências linguísticas e sobre fundamentos e estratégias que possibilitem "refazer princípios e crenças" dos estudantes em ambiente acadêmico é evidenciada por Marinho. A autora demonstra que existe uma relação "tímida", "inadequada" e "ineficiente" desses estudantes com as práticas acadêmicas letradas. Nessa mesma linha, Silva e Castanheira, ao investigarem "as condições em que a escrita acadêmica é solicitada em cursos de graduação" com o intuito de compreender essas práticas, evidenciam que existe uma grande e variada demanda de gêneros do discursos para serem lidos e produzidos nesse contexto; no entanto as práticas de letramento denotam situações escolarizadas e revelam que ainda temos muitos desafios quando se trata de letramento acadêmico.

Em se tratando do contexto específico deste estudo, formação inicial de professores de língua portuguesa, realizamos uma rápida busca no site da Biblioteca Digital Brasileira 
de Teses e Dissertações (BDTD) e localizamos, quinquênio 2015-19, quatro estudos que focalizam eventos e práticas de letramento de estudantes de Letras. Em sua maioria, a discussão recai em práticas de letramento digital como em Santos (2015), que analisou o processo de desenvolvimento do letramento informacional digital de professores; e de Carvalho (2019), que verificou como estão sendo realizadas atividades de leitura e escrita acadêmicas, diante do desenvolvimento das Tecnologias da Informação e Comunicação.

Considerando os estudos apresentados, objetivamos, neste artigo, investigar de que forma professores de língua portuguesa em formação inicial (res)significam suas práticas de letramento no contexto acadêmico. Para cumprir esse propósito, este artigo está organizado em 3 movimentos, além desta introdução e das considerações finais. No primeiro, revisamos a perspectiva teórica que fundamenta a nossa análise, Novos Estudos do Letramento, discutindo os conceitos de eventos e práticas de letramentos e a perspectiva de letramentos acadêmicos. Na segunda parte, descrevemos o nosso percurso metodológico em termos de contexto de pesquisa, geração de dados e procedimentos de análise. Por fim, sumarizamos os resultados e discutimos as implicações deste estudo.

\section{Novos estudos do letramento}

Os Novos Estudos do Letramento emergem de uma virada paradigmática que considera os aspectos ideológicos das práticas letradas. Nesse sentido, "é possível perceber que o 'como' as pessoas usam a escrita está estreitamente ligado a detalhes específicos da situação em que são usados [os textos] e que os eventos de letramento são particulares de uma comunidade específica" (TERRA, 2010, p.47). Dessa forma, podemos afirmar que cada comunidade detém modos particulares de usar os textos que, em grande medida, revelam as relações de poder ali instituídas. Para Barton e Hamilton (2000), o letramento pode ser compreendido como um conjunto de práticas sociais, modeladas pelas instituições sociais:

Instituições socialmente poderosas, como a educação, tendem a apoiar práticas de letramento dominante. Essas práticas dominantes podem ser vistas como parte da formação total de um discurso, configurações institucionalizadas de poder e conhecimento as quais são corporificadas nas relações sociais. Outros letramentos vernaculares que existem no dia a dia das pessoas são menos visíveis e menos 
apoiados. Isso significa que práticas de letramento são modeladas por instituições sociais e relações de poder, e alguns letramentos são mais dominantes, visíveis e influentes que outros ${ }^{1}$. (BARTON; HAMILTON, 2000, p. 12)

Em razão disso, o letramento somente pode ser entendido quando consideramos seu lugar historicamente situado. Para melhor compreender essa visão, faz-se necessário conceituar eventos e práticas de letramento.

Os eventos de letramento são entendidos como "atividades nas quais o letramento tem uma função. [...] Eventos são episódios observáveis que surgem das práticas e são moldados por elas"2 (BARTON; HAMILTON, 2000, p. 8). Barton (1993, p.8) define "práticas de letramento como os modos culturais gerais de usar a leitura e a escrita que as pessoas produzem em um evento de letramento". Segundo Street (1998), o conceito surgiu para dar conta tanto dos episódios observáveis quanto de “[...] modelos sociais de letramento que os participantes levam para esses eventos e que dão sentido a eles”.

Dessa forma, a concepção de práticas de letramentos envolve um olhar que se estende aos modos de pensar e de lidar com a leitura e a escrita em cada contexto cultural (STREET, 2000). Portanto, esse conceito envolve e amplia o conceito de eventos de letramento para dar conta de relações de poder, ideologia e identidades. Para Castanheira e Street (s/ano) $)^{3}$, práticas e eventos de letramento são modelos analíticos utilizados por pesquisadores que buscam compreender os usos e os significados da escrita e da leitura para diferentes grupos sociais e as consequências educacionais, políticas e sociais de tais usos e significados para os indivíduos e para os grupos a que pertencem.

\footnotetext{
1 "Socially powerful institutions, such as education, tend to support dominant literacy practices. These dominant practices can be seen as part of whole discourse formation, institutionalised configurations of power and knowledge which are embodied in social relationship. Other vernacular literacies which exist in people's everyday lives are less visible and less supported. This means that literacy practices are patterned by social institutions and power relationships, and some literacies are more dominant, visible and influencial than others".

2 "literacy events are activities where literacy has a role. [...] Events are observable episodes which arise from practices and are shaped by them".

${ }^{3}$ Glossário Ceale - Termos de Alfabetização, Leitura e Escrita para educadores. Faculdade de Educação - UFMG. 
Neste trabalho, focalizamos o contexto acadêmico que tem sido objeto de investigação de diversos pesquisadores (BARTON; HAMILTON, 1998; LEA; STREET, 1998, LILLIS, 2001; LEA, 2004). Pesquisadores desse campo concebem o letramento como prática social e proclamam que o letramento é mais que o conhecimento do código da língua, já que se refere aos usos e às funções da escrita dentro das práticas sociais em que se insere (LEA; STREET, 1998; STREET, 2003).

Um dos estudos considerados referência para a constituição desse campo foi realizado por Lea e Street (1998). Os autores realizaram uma pesquisa empírica em duas universidades distintas, no Reino Unido, a fim de examinar os textos dos alunos em um contexto de práticas institucionais, relações de poder e identidades. Esse estudo possibilitou a identificação de lacunas na forma como alunos e professores compreendiam a produção textual. Os resultados da pesquisa apontaram três modelos de letramento no contexto universitário: modelo das habilidades de estudo, modelo de socialização acadêmica e modelo do letramento acadêmico.

Para os autores, o modelo de habilidades de estudo concebe a escrita como habilidade individual e cognitiva, cujo foco recai em aspectos da estrutura da língua, pressupondo que os estudantes podem transferir seus conhecimentos de escrita de um contexto para outro. O modelo de socialização acadêmica refere-se ao processo de aculturação de estudantes em discursos e gêneros baseados nos temas e nas disciplinas. Esse modelo supõe que os discursos disciplinares e os gêneros são relativamente estáveis e, uma vez que os estudantes tenham aprendido e entendido as regras básicas de discurso acadêmico particular, estão aptos a reproduzi-lo sem obstáculo. Por fim, o modelo de letramento acadêmico entende a escrita como produção de sentidos, identidade, poder e autoridade, colocando em primeiro plano a natureza institucional daquilo que conta como conhecimento em qualquer contexto acadêmico específico.

Os autores sinalizam que esses três modelos não se excluem mutuamente, pelo contrário, sobrepõem-se em determinados contextos. Street (2010, p.546) argumenta que o modelo dos letramentos acadêmicos é o que melhor leva em conta "a natureza da produção textual do aluno em relação às práticas institucionais, relações de poder e identidade; em 
resumo, consegue contemplar a complexidade da construção de sentidos, ao contrário dos outros dois modelos".

Buscamos, assim, examinar de que maneira os alunos ressignificam suas práticas de letramento no contexto acadêmico, tendo por base sua participação em eventos de letramento na escola e na universidade e de sua visão sobre produção de textos na escola e na universidade. Acreditamos que essa análise poderá lançar luz sobre os significados da escrita no contexto investigado, evidenciando como as práticas de escrita descritas pelos participantes podem estar associadas aos modelos de ensino da escrita caracterizados acima (habilidades, socialização e letramentos acadêmicos).

\section{Universo, corpus e procedimentos de análise}

O universo desta pesquisa compreende um grupo de 31 professores de língua portuguesa em formação inicial, matriculados na disciplina de produção textual, ofertada no segundo semestre de um curso de licenciatura Letras - Português de uma universidade pública do interior do estado do Rio Grande Sul. A maioria desses participantes são jovens (entre 18 e 20 anos) e cursaram o ensino básico em escolas públicas. Em relação à graduação, grande parte dos estudantes afirma ter escolhido cursar letras devido ao seu amor por ensinar e ao seu gosto pela leitura e escrita. A participação em projetos de pesquisa e extensão já está presente na vida de muitos desses jovens (52\%), representando um engajamento acadêmico bastante interessante, já que se encontram no início da graduação. Importante sinalizar que $12 \%$ desses participantes possuem graduação em outras áreas, quais sejam: Comunicação Social com Habilitação em Jornalismo, Direito, Pedagogia e Letras com Habilitação em Língua Espanhola e suas respectivas literaturas.

Como instrumento de geração de dados, aplicamos um questionário semiestruturado no primeiro dia de aula da disciplina. Dessa forma, o corpus de análise é constituído das respostas fornecidas pelos estudantes a cinco questões, quais sejam: i) como se aprende a produzir textos, ii) o que caracteriza um “bom” texto, iii) há diferenças entre produzir textos na escola e na universidade, iv) de que forma acontece a aprendizagem de produção 
textos no contexto acadêmico e v) quais suas principais dificuldades para produzir textos acadêmicos.

As respostas dos participantes foram transcritas dos questionários, e os participantes foram identificados como P1, P2...P31 a fim de manter o anonimato. Os procedimentos de análise compreenderam três etapas: i) identificação dos recursos ricos em significação ${ }^{4}$ e elaboração de categorias semânticas de análise, ii) comparação entre as práticas letradas experienciadas na universidade e escola e iii) verificação da proximidade/distanciamentos entre as práticas descritas.

\section{Análise e discussão dos resultados}

Os estudantes, quando ingressam no ensino superior, "trazem consigo seus próprios mapas de lugares e desejos comunicativos que lhes são familiares" (BAZERMAN, 2006, p. 24), evidenciando que o caminho discursivo a ser percorrido precisa ser mediado por pares mais experientes para que possam se apropriar de novas paisagens discursivas. Nesse sentido, Bazerman argumenta que a escolha dos gêneros, que serão produzidos pelos alunos, deve estar ancorada nas percepções que esses produtores possuem "sobre a direção para onde estão indo e sobre seus sentimentos a respeito dos lugares que lhes indicamos" (BAZERMAN, 2006, p. 24).

Partindo desse pressuposto, a compreensão dos eventos e práticas de letramento dos quais os estudantes participam pode sinalizar caminhos interessantes a serem trilhados pelos professores formadores a fim de que os professores em formação ressignifiquem suas práticas de leitura e escrita. Com esse intuito, ao analisarmos as respostas dos participantes, identificamos que o processo de aprendizagem da escrita representa uma ação individual para a maioria dos participantes, refletindo os princípios de um modelo de letramento

\footnotetext{
${ }^{4} \mathrm{~A}$ identificação dos elementos ricos em significação está relacionada à sua recorrência. Os elementos ricos em significação podem ser "qualquer elemento linguístico em um texto ou em um conjunto de textos que sugere a maneira como o significado é incorporado no texto e sua conexão com o contexto" (BARTON, 2004, p. 66).
} 
como habilidade neutra. Ao afirmar como se aprende a escrever, enfatizam a leitura, especialmente, como forma de ampliação do seu repertório linguístico:

P3 Por experiência própria, posso dizer que sem o hábito de leitura é muito difícil escrever, faltam palavras adequadas para encaixar em uma frase $[\ldots]$.

P13 Através da leitura. Acredito que ler enriquece o vocabulário e estimula nossa criatividade, possibilitando a produção de bons textos.

P29 Ao meu ver, para produzir um bom texto, primeiramente é importante ter um leque de palavras bem amplo e saber usá-las nos momentos oportunos.

Os estudantes parecem entender que o processo de produzir está relacionado à apropriação novas de palavras, limitando, em alguma medida, a unidade de sentido à frase conforme afirmado por P3. Ainda que P29 corrobore a ideia de que um vocabulário amplo contribui para a produção de bons textos, há a sinalização, mesmo que tímida, da expressão "momentos oportunos", indicando que somente um "leque de palavras" não seja suficiente se não for observada a situação discursiva em que serão usadas. Nesse sentido, começamos a observar uma ressignificação das práticas de produção, já que alguns participantes acrescentam à ampliação de reportório linguístico que é necessário o “[...] entendimento das características dos gêneros textuais" (P20) e "deixar outras pessoas ler para avaliarem ou criticarem" (P4).

Em relação às características atribuídas à construção de um bom texto, os participantes apontam a clareza como o fator mais relevante, reforçando a perspectiva de produção como um ato individual como em " [...] um bom texto é aquele que comunica bem suas ideias" e "um texto que esteja claro e coerente". Ao apresentar a clareza como principal característica, há também a consideração do leitor e do autor:

P3 Um bom texto é aquele que transmite clareza ao leitor [...].

P5 O público alvo importa muito, mas para mim sempre tem que ser um texto claro, com linguagem simples.

P9 Quando o autor consegue expor suas ideias de forma organizada e clara. 
A tensão sinalizada pelo participante P5 evidencia que o processo de escrita ainda não pode ser visto como uma ação social em um determinado contexto de atuação. Ao incluir o público leitor como aspecto a ser considerado, parece estar refletindo acerca do contexto de circulação e consumo do texto. Isso, no entanto, é minimizado quando introduz o operador argumentativo "mas" e constrói uma relação de equivalência entre clareza e linguagem simples. Nesse sentido, há uma visão de que o texto não depende do contexto para ser "claro", visto que é preciso apenas que se "use bem as questões ortográficas e as questões gramaticais". Essa característica, "de ser claro", está diretamente ligada à função atribuída ao texto que é a de "comunicar alguma coisa, de passar determinada lição".

Nessa mesma linha, a estrutura e a gramática e/ou ortografia surgem como aspectos de grande relevância para os estudantes. Embora os professores em formação sinalizem a relevância de uma adequação à estrutura, o significado do conceito parece variar, por exemplo, para P6: “[...] na minha experiência, é a organização do texto em introdução, desenvolvimento e conclusão", já para P13, "depende do tipo de texto e os critérios correspondentes a cada um tecnicamente [...]”. Essa tensão, já evidenciada anteriormente, indica que os estudantes estão se apropriando de uma escrita situada, com vistas a atuação em comunidades discursivas, conforme argumenta P20 em "para um texto ser considerado bom, na minha perspectiva, ele deve cumprir seu objetivo comunicativo".

As práticas de letramento evidenciadas pelos estudantes mostram-se fortemente marcadas por uma visão de língua centrada na uniformidade dos níveis de registros da linguagem e na crença de sua capacidade de ser transparente. Assim, para muitos dos participantes, a língua é vista como desvinculada de seus diversos usos e de qualquer contexto de produção e consumo. Escrever é, portanto, transferir para o papel os pensamentos, as ideias e os sentimentos já construídos de antemão na mente. Através do bom uso das normas gramaticais e ortográficas assim como de um vocabulário rico e variado, o indivíduo seria capaz de expressar-se de modo a comunicá-los da melhor forma possível.

Considerando os eventos de letramento dos quais os estudantes participavam no contexto escolar, especificadamente no ensino médio, constatamos a leitura frequente de 
livros didáticos e de ficção, provas e atividades didáticas. A escrita parece estar restrita à prática de estudo e à produção de exemplares para provas seletivas:

P1 Lia textos sobre possíveis temas para a redação do ENEM.

P2 Na escola, uma vez por semana, a gente contava o livro que estávamos lendo e, em seguida, fazíamos resumos para entregar.

P4 Costumava ler livros infanto-juvenis, algumas obras literárias brasileiras e os textos solicitados pelos professores. Quanto à escrita, somente redações para o ENEM [...].

P12 Não costumo escrever como alguns dos meus colegas, mas quando preciso estudar [...] faço resumos sobre o conteúdo.

A16 Na escola eu lia muitas obras da prosa romântica, e paralelamente, algumas obras de distopias para o público jovem. A escrita mantinha-se restrita produção textual para o ENEM e vestibulares. A17 Além disso, lia os textos do livro didático que eram necessários para a realização de questões objetivas e dissertativas.

Usos da leitura e da escrita nesse contexto revelam uma prática voltada para realização de tarefas exigidas pelos professores, cuja finalidade maior é o processo seletivo do Enem. No entanto, vislumbramos um uso bastante particular do gênero resumo citado pelos participantes P2 e P12. Enquanto o participante P2 usa a escrita do gênero resumo como forma de avaliação/validação das suas atividades de leitura, P12 produz resumos dos conteúdos com vistas ao estudo. Interessante refletir que a produção de P12 está relacionada a sua necessidade de aprender novos conteúdos, revelando um propósito desse gênero tipicamente escolar e também acadêmico.

A transição para o contexto acadêmico revela uma ruptura com o contexto escolar, já que a ampla maioria entende que há diferenças entre produzir em um e outro contexto:

P6: Apesar da leitura e da escrita serem pouco influenciadas nas minhas escolas eu sinto que sim, há muita diferença, tanto com a formalidade das leituras e produções quanto a frequência das mesmas.

P7: Com toda certeza. A linguagem acadêmica requer certas formalidades características que na escola não são contempladas.

P13: Não tive contato (ainda) com a produção de textos, mas as leituras na universidade são muito diferentes da escola, são mais difíceis e técnicas.

Apesar de perceberam como práticas de letramento distintas, contexto acadêmico e escolar, as diferenças parecem estar centradas em aspectos como grau de formalidade e 
de tecnicidade. Nesse sentido, ao participarem de eventos de letramentos no contexto acadêmico, $71 \%$ dos participantes acreditam que o processo de aprendizagem de escrita acontece quando há transmissão de conhecimentos e desenvolvimento de habilidades de escrita, visto que é um processo individual em que regras e normas devem ser apreendidas:

P3 Durante a escrita, o conhecimento é assimilado e, entendo, também, que as normas podem atender a parte lógica, pois precisamos estar atentos às regras.

P6 Acredito que uma boa instrução sobre normas e regras gramaticais torna mais eficiente a produção textual dos alunos.

P10 Eu vejo a escrita de maneira individual, um processo de quase solidão [entre o] autor e o texto.

P13 Transmissão de conhecimento, para mim, é a palavra-chave, visto que só escrevemos bem sobre algo quando conhecemos bem o assunto.

P24 Acredito que quando tu lê e ouve as explicacõos da professora, acontece essa transmissão de conhecimentos e de desenvolvimento de habilidades de escrita [...] temos que aprender estratégias $\underline{\text { sozinhos para facilitar nossa produção textual. }}$

Tal perspectiva parece evidenciar os eventos de letramentos já experienciados no contexto escolar. Dessa forma, a formação desses profissionais sinaliza uma visão de como se aprende: repetindo e acumulando saberes, quase sempre de ordem estrutural da língua, privilegiando aspectos gramaticais e normativos.

Por outro lado, 18\% dos professores em formação sinalizam irão aprender no momento em que se apropriarão dos modos de falar, escrever, pensar e usar os textos que caracterizam os membros dessa comunidade:

P5 No ambiente acadêmico, num curso especifico, todos estão aprendendo as mesmas coisas, estão em sintonia nos assuntos, aprendem a falar, a escrever e a pensar de acordo com a sua graduação, então é um processo que caracteriza esse público.

P7 A imersão no ambiente acadêmico preconiza a construção gradual do entendimento e da produção escrita acadêmica e suas formalidades. Essa imersão corre tanto pelos textos para serem lidos quanto para a explanação oral do professor.

Nesse sentido, há para esse grupo de professores uma ressignificação dos eventos e práticas de letramento experienciados nesse novo contexto de atuação. Isso pode ser evidenciado quando é percebida a comunidade da qual estão fazendo parte como em "processo que caracteriza esse público". 
Para 11\% dos participantes, as práticas de leitura e escrita são vistas como complexas e dinâmicas, situadas e envolvidas por relações de poder entre pessoas, instituições e identidades sociais:

P18 Quando se reconhece que existem diferentes modos de falar, oriundos de múltiplas identidades que constituem a sociedade, percebe-se a necessidade de possibilitar o acesso a diferentes leituras.

Importante sinalizar que os professores em formação que apontam as práticas como envoltas de relação de poder são leitores e escritores mais experientes em termos de reflexões teóricas e práticas que sustentam o ensino de linguagem no contexto escolar, já que possuem graduação em outras áreas.

Em relação às dificuldades enfrentadas pelos professores em formação para contexto no contexto acadêmico, novamente surgem aspectos relacionados ao ato individual de produzir conforme já sinalizado anteriormente: "P27 Com toda certeza o uso correto das palavras, bem como da estrutura dos textos”, P28 A estruturação dos textos” e P27 “O domínio da linguagem".

Essa visão da produção como um ato individual, que depende apenas do sujeito como se não estivesse inserido em contextos de limitações que transcendem a sua ação exclusivamente individual, reforça a crença de que o sucesso ou fracasso relaciona-se a sua atuação exclusivamente. Romper com discursos naturalizados significa (re)construir o seu fazer e tomar consciência de que existem questões maiores, conforme sinaliza P6 e P13 em: "Sinto dificuldades em relação a formalidade dos textos, acredito que não tenho um bom suporte para produzir textos formais" e P13: "A falta de experiência e a insegurança quanto a qualidade do material produzido, pois parece que se exige sempre mais do que sabemos". Além disso, revela os saberes construídos no contexto escolar e que, em alguma medida, distanciam-se dos saberes requeridos no contexto acadêmico. 


\section{Considerações finais}

As questões discutidas neste artigo buscaram investigar, em alguma medida, como professores de língua portuguesa em formação inicial (res)significam suas práticas de letramento no contexto acadêmico. Ao atentarmos para a heterogeneidade presente em seus discursos, percebemos que os professores em formação entendem o seu processo de letramento como um ato individual e que a efetiva participação em práticas letradas acontecerá quando houver a apropriação de regras gramaticais e a ampliação de seu reportório linguístico.

Ainda que as práticas de letramento revelem indícios de um modelo de letramento autônomo, centrado na aquisição de habilidades individuais, observamos também certa tensão entre o que é esperado do estudante no contexto escolar e os saberes requeridos no contexto acadêmico. Isso se efetiva quando há a (res)significação de suas práticas ao perceberem que a aprendizagem de regras gramaticais parece não ser suficiente para interagir no ambiente acadêmico. Assim, constatamos que a (res)significação ocorre quando existe um olhar para o uso da escrita como um processo de socialização. Mesmo que tímido e talvez até desempoderado ainda, os estudantes começam a construir modelos de letramento que incluem uma comunidade específica, no caso o curso letras.

Com o sentimento de pertencer a essa nova comunidade, entre o novo e o antigo, os professores de língua portuguesa em formação sinalizam a necessidade de que sozinhos dificilmente será possível participar de maneira crítica nesse novo contexto, já que "parece que sempre exigem mais" do que efetivamente eles sabem. Dessa forma, os dados analisados reforçam que a compreensão dos usos da escrita é fundamental para refletirmos sobre a formação do professor a fim promover práticas de leitura e escrita que perspectivem o letramento acadêmico de fato. Apresentamos, neste relato, resultados parciais sobre o contexto analisado e que, em grande medida, darão sustentação à disciplina de Produção textual. Por fim, concordamos com Marinho quando afirma que a reflexão sobre "princípios e crenças" dos estudantes em ambiente acadêmico pode ser o primeiro passo para a promoção do letramento acadêmico. 


\title{
LITERACY PRACTICES OF PORTUGUESE TEACHERS IN INITIAL FORMATION: BETWEEN SCHOOL AND UNIVERSITY
}

\begin{abstract}
Assuming the literacy studies perspective, the present work investigates how Portuguese teachers (res)signify their textual production literacy practices in the academic context. Therefore, we will start from the concept of literacy events, understood as observable episodes that emerge from practice; and from the concept of literacy practices, understood as the general ways of using writing in events. The analyses universe covers a group of Portuguese teachers in initial formation, enrolled in the Textual Production subject, offered in the second semester of a degree course at a federal university in the interior of the state of Rio Grande do Sul. The data were generated from a semi-structure questionnaire, answered by 31 participants, whose questions showed the teaching and learning process of textual production at school and university. For data analysis, the following procedures were used: i) identification of resources rich in meaning and elaboration of semantic categories of analysis, ii) comparison between the literate practices experienced at university and school and iii) verification of the proximity/distancing between the described practices. The results show that the teachers in formation understand the literacy process as individual, focusing in structural and normative aspects.
\end{abstract}

KEYWORDS: Literacy events and practices; Teachers formation; New Literacy Studies

\section{REFERÊNCIAS}

BARTON, D.; HAMILTON, M. Local Literacies. Reading and Writing in one Community. London/New York: Routledge, 1998.

; _. In: BARTON, D.; HAMILTON, M.; IVANIC, R. Situated literacies Reading and writing in context. Nova Iorque: Routledge, 2004, p. 7-15.

BARTON, E. Linguistic Discourse Analysis: How the Language in Text Works. In: BAZERMAN, C.; PRIOR, P. (Ed.). What Writing Does and How It Does It: An introduction to Analyzing Texts and Textual Practices. New Jersey: Lawrence Erlbaum Associates, 2004. p. $57-82$.

BAZERMAN, C. Judith C. Hoffnagel; Ângela P. Dionísio (orgs). Gêneros, agência e escrita. São Paulo: Cortez, 2006.

FIAD, R, S. A escrita na universidade. Revista da $A B R A L I N$, v. eletrônico, n. especial, t. 2, p. 357-369, 2011. Disponível em: <https://revistas.ufpr.br/\%20abralin/article/view file/32436/20585> Acesso em: 31 jan. 2020.

KLEIMAN, Angela. Modelos de letramento e as práticas de alfabetização na escola. In: - (org.). Os significados do letramento: uma nova perspectiva sobre a prática social da escrita. Campinas: Mercado de Letras, 1995. p. 15-61.

LEA, Mary R. I thought I could write till I came here: Student writing in Higher Education. In: GIBBS, G (ed.) Improving student learning: theory and practice. Oxford: Oxford Centre for Staff Development, 1994. p. 216-226. 
; STREET, Brian V. Student writing in high education: an academic literacies approach. Studies in Higher Education, v. 23, n. 2, p. 157-172, 1998. Disponível em: <https://www.tandfonline.com/doi/abs/10.1080/03075079812331380364> Acesso em: 20 jan. 2020.

LILLIS, Tereza. Student writing: access, regulation, desire. London: Routledge, 2001.

STREET, Brian. Eventos de letramento e práticas de letramento: teoria e prática nos novos estudos do letramento. In: MAGALHÃES, I. (org.). Discursos e práticas de letramento. Campinas: Mercado de Letras, 2012. p. 69-92.

. Literacy in Theory and Practice. New York: Cambridge University Press, 1984.

What's new in New Literacy Studies: critical approaches to literacy in theory and practices. Current Issues in Comparative Education. Columbia University, v. 5, n.2, p. 77-91, 2003.

TERRA, M. R. Letramento \& letramentos: uma perspectiva sócio-cultural dos usos da escrita. DELTA [online], vol.29, n.1, 2013. Disponível em: <http://www.scielo.br/ scielo.php?script=sci_arttext\&pid=S0102-44502013000100002> Acesso em: 07 fev. 2020.

Recebido em: 30/04/2020.

Aprovado em: 20/05/2020.

\section{AGRADECIMENTO}

Agradecemos às colegas integrantes do Núcleo de Estudos e Pesquisas em Ensino de Linguagem, Taís Vasques Barreto e Verônica Lorenset Padoin, pela organização e sistematização do corpus do presente trabalho. 